\title{
THE JUNE MEETING IN CORVALLIS
}

The six hundred eighty-sixth meeting of the American Mathematical Society was held at Oregon State University, Corvallis, Oregon, on Saturday, June 19, 1971. This meeting was held in conjunction with a Northwest Sectional meeting of the Mathematical Association of America. There were 168 registrants at the meeting, including 109 members of the Society.

By invitation of the Committee to Select Hour Speakers for Far Western Sectional Meetings, there were two invited hour addresses at this meeting. Professor Ky Fan of the University of California at Santa Barbara lectured on Fixed point theorems in functional analysis. Professor Victor L. Klee introduced Professor Ky Fan. Professor Robert J. Blattner of the University of California at Los Angeles presented the second hour address. The title of his talk was Linearly compact Lie modules. He was introduced by Professor Charles W. Curtis.

There were four sessions of contributed ten minute papers, chaired by Professors Richard Koch, Mysore N. L. Narasimhan, Bent E. Petersen, and Vincent Williams.

EUGENE, OREGON

Kenneth A. Ross Associate Secretary 